\title{
EDITORIAL
}

\section{Aboagora-between arts and sciences}

\section{T} he current issue of Approaching Religion gathers together papers, statements and reflections presented at the multidisciplinary symposium Aboagora-Between Arts and Sciences, held in Turku in August 2011. The aim of this experimental seminar was to initiate a dialogue between the arts and sciences, to establish new kinds of discussion forums for artists and academics and to make this collaboration available for the benefit of a larger audience. The name Aboagora refers to the Latin name for Turku, Aboa, and to the agora as an open forum for thinking. This particular agora brought together musicians, poets, filmmakers, dancers and actors with scholars from such varied fields as neurosciences, medicine, education, social sciences and the humanities.

AвOAgora WAS REAlised as a joInt effort by the Donner Institute, Turku Music Festival and the Department of Cultural History at the University of Turku. The programme of the music festival offered a unique framework for this dialogue between art and sciences, as the musicians attached to the festival joined the academic discussions in panels and workshops, bringing their artistic comments to the topics under discussion. In this journal, we can unfortunately only print the contributions that were put down in words on paper, but it is important to note that the open agora facilitated during the three-day seminar included voices from the performing arts as well.

During the year 2011, Turku has been the European Capital of Culture, and it is within these frames that the first ever Aboagora seminar was arranged. The theme of the symposium was 'Rethinking Enlightenment' and sought to critically examine the Enlightenment heritage and its conse-

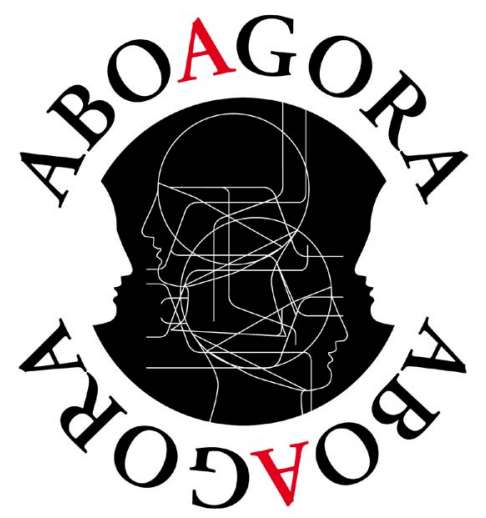

quences for our binary understanding of arts versus sciences today. Our modern world, and especially the Western academic tradition, is in many ways a product of the eighteenth century and the culture of the Enlightenment. During the seminar, many of the dichotomies that characterise Enlightenment thinking were discussed and challenged in a border-crossing, innovative climate created by unprejudiced combinations of scholars from different fields, musicians, artists and the public. To quote the words of Yehuda Elkana, member of the advisory board of Aboagora, which were printed in the programme booklet of Aboagora:

Rethinking-not unthinking-the Enlightenment makes us abandon the dichotomising approach to life and its problems, and develop rather a dialogical approach. The kinds of polar pairs that we have to abandon are for example: theory/practice; enemy/friend; rational/irrational; internal/external; and, for our case most importantly, the art/science dichotomy. There is no such thing as par excellence scientific think- 
ing, or typical artistic thinking. Both rely on intuition, on explicit and tacit knowledge, on empirical data and on the need to ignore them sometimes.

The seminar consisted of several workshops, lectures and concerts - a number of which are represented in this issue of Approaching Religion. This editorial is followed by a the introductory statement that opened the conference, given by Yehuda Elkana. It is printed as a transcript of the speech delivered in situ in Turku. The same applies to the concluding statement by Helga Nowotny, printed in this issue: it is an edited address based on a transcript of the statement given right there, right then, at the end of the conference.

Between the introduction and the conclusion, this issue is divided into two sections, gathering together presentations delivered in two different Aboagora workshops: 'Rethinking the Notion of Culture', dealing with the conceptual roots and contemporary challenges connected to the notion of culture, and 'Eighteenth Century Enlightenment and Its Heritage', presenting analyses of this era by several young scholars of today. Some of the workshop presentations have been developed into full-scale articles, others still preserve the character of spontaneous comments and responses, delivered as part of a dynamic and interdisciplinary discussion in an open agora of thoughts and viewpoints. Not only are the formats and viewpoints presented in this issue rich in diversity: the contributors also make up quite a colourful palette, ranging from Bachelor students to $\mathrm{PhD}$ Candidates, senior researchers, professors and emeriti. The issue closes with three personal reflections on the theme of Aboagora and the experience of taking part in the Aboagora. The finale also includes a reprinted excerpt from a story written by Ruth Behar, professor of Anthropology as well as poet and documentary filmmaker. Behar read this story as an artistic comment within a workshop entitled 'Between Art and Research: Rethinking Professional Borderlands', dealing with the experiences of persons who combine an academic profession with artistic work.

Within the editorial team, we are grateful to note that the inaugural issue of our journal has reached a vast number of readers: the articles have been downloaded hundreds of times and we have received a lot of feedback and suggestions from readers involved in the area of research represented by the Donner Institute. Above all, we are happy to announce that Approaching Religion has merited inclusion in the international academic Directory of Open Access
Journals (DOAJ). This way, our articles are now easy to find through databases and library catalogues in universities all over the world.

RUTH ILLMAN

Editor

\section{References}

Aboagora. Conference website. http://www.aboagora.fi

The Donner Institute for Research in Religious and Cultural History website. http://web.abo.fi/instut/di/english/index.html

Turku Music Festival website. http://www.tmj.fi

University of Turku, Cultural History website. http://www.hum.utu.fi/oppiaineet/kulttuurihistoria/en/

\section{Aboagora lectures on the Internet}

http://www.youtube.com/user/Aboagora

http://aboagora.wordpress.com/ 